\title{
Status and Solidarity in Social Comparison: Agentic and Communal Values and Vertical and Horizontal Directions
}

\author{
Kenneth D. Locke \\ University of Idaho
}

\begin{abstract}
Social comparison involves positioning the self relative to others on a vertical or status dimension (ranging from upward to downward comparisons) and a horizontal or solidarity dimension (ranging from contrastive to connective comparisons). Across 3 studies in which 389 undergraduates recorded everyday social comparisons $(n=4,417)$, downward and connective comparisons were rated as more helpful and mood enhancing than upward and contrastive comparisons. The effects of horizontal comparisons were greater for people for whom solidarity was an important value; however, the effects of vertical comparisons were not greater for people who valued status. The roles of the comparison target, topic, and situation were also explored; for example, noticing undesirable features of the target enhanced status but undermined solidarity.
\end{abstract}

A large body of literature suggests that when people think about the relations between individuals, they think in terms of two broad dimensions - one of status, power, dominance, or agency, and one of solidarity, intimacy, friendliness, or communion (for a brief overview, see Wiggins \& Trobst, 1999; for a variety of broader theoretical statements, see Bakan, 1966; R. Brown, 1965; Carson, 1969; and Foa \& Foa, 1974; for a more recent review of relevant literature, see Kiesler, 1996). Factor analyses confirm that these two dimensions account for a large proportion of the variance in ratings of interpersonal behaviors and traits (e.g., Conte \& Plutchik, 1981; Foa, 1961; Wiggins, 1979), and also may explain much of the variance in ratings of open-ended person descriptions (Heck \& Pincus, 2001). In addition, these two dimensions are important themes in narrative measures of implicit motives and autobiographical memories (e.g., McAdams, 1982; Woike, Gershkovich, Piorkowski, \& Polo, 1999).

Researchers have successfully used the combination of these two axes to (a) identify the interpersonal meanings of nonverbal behaviors (Gifford, 1991); (b) create empirical taxonomies of various positive interpersonal traits and behaviors, such as social competence (Gurtman, 1999) and social support (Trobst, 2000); and (c) specify the interpersonal correlates of psychological problems such as depression (Bieling \& Alden, 2001; Zuroff, Moskowitz, \& Cote, 1999), social anxiety (Alden \& Phillips, 1990), perfectionism (Hill, Zrull, \& Turlington, 1997), and the Diagnostic and Statistical Manual of Mental Disorders (American Psychiatric Association, 1987) personality disorders (Matano \& Locke, 1995; Widiger \& Hagemoser, 1997) and related personality styles such as narcissism (Bradlee \& Emmons, 1992; Ruiz, Smith, \& Rhodewalt, 2001), psychopathy (Salekin, Trobst, \& Krioukova, 2001), and dependency (Pincus \& Wilson, 2001). These dimensions have

I am very grateful to Dennis Baughman, Shoshana Peyser, and Tom Sneed for helping me collect and enter the data.

Correspondence concerning this article should be addressed to Kenneth D. Locke, Department of Psychology, University of Idaho, Moscow, Idaho 83844. E-mail: klocke@uidaho.edu also proven useful in guiding and interpreting experimental research on how people respond to complaints (Horowitz et al. 1991) and to bids for social support (Horowitz et al., 2001).

\section{Status and Solidarity in Social Comparisons}

If people think about the relations between individuals in terms of status and solidarity, then social comparison-which has been defined as "the process of thinking about information about one or more other people in relation to the self" (Wood, 1996)—should involve thinking about the status and solidarity of others in relation to the self. Of course social comparisons involve more than status and solidarity relative to a particular comparison target. One reason social comparison has been such a vital area of research is that comparisons affect so many important mediators of behaviorsuch as self-esteem, judgments of fairness, and outcome and efficacy expectancies-that are distinct from and transcend the relationship with any particular comparison target. Nonetheless, whatever other implications a social comparison carries, it starts with information about the self in relation to particular persons. To that extent social comparison is an interpersonal act, and thus is likely to engage the key interpersonal dimensions of status and solidarity.

Typically, however, social comparison research has emphasized the status dimension and neglected the solidarity dimension. Consider the "direction" of a social comparison. If there are two central interpersonal axes, then there are four cardinal directions: above, below, together, and apart. However, comparison direction traditionally has referred only to the vertical or status dimension- that is, whether the comparison target is perceived as standing above the self (an upward comparison) or below the self (a downward comparison). Indeed, distinguishing the emotional and motivational antecedents and consequences of upward and downward comparisons has probably received more attention than any other topic in the social comparison literature (see Collins, 1996; Wills, 1991).

In contrast, the social comparison literature has devoted little attention to the horizontal or solidarity dimension-that is, 
whether the comparison target is perceived as sharing an aspect in common (a connective comparison) or not (a contrastive comparison). Moreover, when connective and contrastive comparisons have been assessed, it typically has been in order to predict the targets and outcomes of vertical comparisons. A number of early comparison studies tested Festinger's (1954) hypothesis that people would prefer targets who are similar with respect to the attribute being compared. Later, studies tested Goethals and Darley's (1977) hypothesis that, on the basis of attribution theory, people would prefer to compare abilities with targets who share attributes relevant to those abilities. In both models, similarity matters because it can strengthen or weaken the informational value of the comparison, not because it has intrinsic significance. Other studies have tested whether people prefer targets with whom they share a distinctive characteristic even if that characteristic is irrelevant to the attribute being compared (Miller, Turnbull, \& McFarland, 1988). Here, again, similarity is a predictor of comparison preferences, not a focus of comparison itself.

Finally, a number of recent studies have shown that what promotes assimilation (self-evaluations going up after upward comparisons and down after downward comparisons) instead of contrast effects (self-evaluations going up after downward comparisons and down after upward comparisons) is perceiving connections with the target-for example, sharing membership in a group (Brewer \& Weber, 1994; Mussweiler \& Bodenhausen, 2002), sharing a close relationship (Pelham \& Wachsmuth, 1995), potentially sharing the same happy or unhappy fate (Lockwood, 2002; Lockwood \& Kunda, 1997), sharing a birthday (J. D. Brown, Novick, Lord, \& Richards, 1992), or priming a sense of the self as socially integrated versus differentiated (Stapel \& Koomen, 2001). Once again, these studies tested the effects of comparing status on evaluating status, and simply used solidarity to predict whether assimilation or contrast would predominate. Thus, each of these research areas framed status as the foreground or focus of social comparisons and subsequent self-evaluations, and framed connective and contrastive information as a moderating background or context. The model underpinning this article conceptualizes both status and solidarity as potential foci of comparisons and subsequent judgments.

\section{Affective Consequences of Comparison Direction}

If horizontal and vertical comparisons are both intrinsically important to people, then each dimension should have an important and independent effect on how people feel. What is the evidence that they do? The effects of vertical comparisons appear to depend on many factors, including qualities of the comparer such as depression, self-esteem, and perceived threats to self-esteem (e.g., Wheeler, 2000; Wood \& Lockwood, 1999), qualities of the target such as perceived similarity on surrounding characteristics and closeness (e.g., Collins, 1996; Tesser, 1991), and qualities of the characteristic being compared such as self-relevance and controllability (e.g., Tesser, 1991; Testa \& Major, 1990). However, studies of naturalistic social comparison show that in general people feel better when they perceive themselves to be superior as opposed to inferior to others (Giordano, Wood, \& Michela, 2000; Locke \& Nekich, 2000; Olson \& Evans, 1999; Van der Zee et al., 1996; Wheeler \& Miyake, 1992).
Although the social comparison literature has devoted less attention to the effects of horizontal comparisons, there is still research relevant to the topic. In particular, just as the social comparison literature was becoming increasingly concerned with vertical comparisons beginning in the early 1960s, the interpersonal attraction literature was becoming more concerned with attitudinal similarity. Numerous studies found that shared attitudes typically evoke positive feelings and facilitate interpersonal attraction whereas contrasting attitudes produce the opposite effects (Byrne, 1971). Analogous results have been found for demographic characteristics (Newcomb, 1961) and personality characteristics (Byrne, Griffitt, \& Stefaniak, 1967; Carli, Ganley, \& Pierce-Otay, 1991). In addition, people find it more comforting to share experiences with others who are experiencing similar apprehensions (Schachter, 1959), moods (Locke \& Horowitz, 1990), or problems (Hegelson \& Taylor, 1993). Finally, diary studies of naturalistic social comparison have also found a strong relationship between perceived similarity and positive affect (Wheeler \& Miyake, 1992), especially feelings of closeness and connection (Locke \& Nekich, 2000).

\section{Individual Differences in the Effects of Comparison Direction}

While downward and connective comparisons generally appear to evoke more positive affect than upward and contrastive comparisons, there may be individual differences in the magnitudes of these effects. People generally have stronger reactions to events that are relevant to subjectively important goals. For example, achievement-related strivings predict stronger emotional reactions to achievement-related events whereas affiliation and intimacy strivings predict stronger reactions to interpersonal events (Emmons, 1991). Similarly, the importance people accord to such values as achievement versus conformity moderates the influence of specific life domains (such as grades vs. family life) on global life satisfaction (Oishi, Diener, Suh, \& Lucas, 1999).

The same may be true for social comparison events. Performing better or worse than another appears to have greater emotional impact when the domain of performance is important to selfdefinition (Tesser, 1991). Moreover, personality traits may predict which topics people consider important. For example, researchers commonly distinguish between two vulnerabilities to depression: insecurity about relationships (i.e., dependency) and insecurity about achievements (i.e., self-criticism; Beck, 1983; Blatt, D'Afflitti, \& Quinlan, 1976). There is some evidence that the emotional impact of vertical comparisons is greater for dependent individuals when comparing interpersonal rather than achievement topics, whereas the reverse is true for self-critical individuals (Giordano et al., 2000). The current studies tested if the emotional impact of comparison direction also varied across individuals. Specifically, vertical comparisons may have a greater emotional impact on people who place greater value on experiencing interpersonal status, and horizontal comparisons may have a greater emotional impact on people who place greater value on experiencing interpersonal solidarity.

Previous research on how traits moderate the impact of comparison direction have typically asked if traits related to self-worth (such as self-esteem and depression) moderate the affective consequences of vertical comparisons (for a review, see Wood \& 
Lockwood, 1999). In other words, does how positively people view themselves overall moderate the emotional impact of how positively they rank on the dimension of comparison? The current research asks a different question: Does the overall importance people accord status and solidarity moderate the emotional impact of their status and solidarity on the dimension of comparison? Both questions are sensible. If comparisons are conceptualized as primarily conveying where the self ranks on the dimension being compared, then global rankings of self-worth are sensible predictors. However, if comparisons are conceptualized as also conveying where the self stands horizontally and vertically in relation to particular others, then agentic and communal values are sensible predictors as well.

\section{Overview of the Studies}

Three studies were conducted. Each study asked the following four questions. (1) Do differences between individuals in the value accorded to status or solidarity predict differences between individuals in comparison direction and the types of feelings evoked by comparisons? (2) Do situational variables (such as the closeness of the target and the type of characteristic being compared) predict variations within individuals in comparison direction and the types of feelings evoked by comparisons? Previous research suggested that comparing with close others or during interactions would be predictive of connective comparisons and communal feelings, whereas comparing objective characteristics (like wealth and beauty) would be predictive of upward comparisons and insecure feelings (Locke \& Nekich, 2000). Comparing with undesirable characteristics might impact both status and solidarity, but in different ways. For example, although people often prefer less fortunate targets when comparing status from a distance, they prefer more fortunate targets when making in person connections (Taylor \& Lobel, 1989).

The effects of the person and the situation on comparison experiences are important questions in themselves, and, to the extent that status and solidarity are influenced in distinct ways, highlight the utility of assessing both status and solidarity during comparisons. However, the key concern of this article is the effect of comparison direction on comparison outcomes, which is the topic of the last two questions. (3) What are the affective consequences of horizontal and vertical comparisons? On the basis of the studies reviewed above, I hypothesized that downward comparisons would evoke more positive reactions than would upward comparisons (and the differences would be greatest for statusrelated feelings such as confidence) and that connective comparisons would evoke more positive reactions than would contrastive comparisons (and the differences would be greatest for solidarityrelated feelings such as intimacy). (4) Do individual differences in the value accorded to status or solidarity explain individual differences in the impact of comparison direction? I hypothesized that communal values would amplify the affective consequences of horizontal comparisons and agentic values would amplify the affective consequences of vertical comparisons.

To assess interpersonal values, participants completed the Circumplex Scales of Interpersonal Values (CSIV; Locke, 2000), which quantify the subjective importance of experiencing varying degrees of status and solidarity in everyday social interactions. To assess naturalistic social comparisons, the studies used an event- contingent self-recording procedure that has been used by a number of social comparison studies in recent years (e.g., Giordano et al., 2000; Locke \& Nekich, 2000; Olson \& Evans, 1999; Wheeler \& Miyake, 1992; Wood, Michela, \& Giordano, 2000). Specifically, each time participants noticed themselves making a social comparison, they recorded the direction of comparison as well as concomitant circumstances and feelings on a Social Comparison Record (SCR). The three studies differed mainly in the specifics of how the SCRs assessed comparison situation, direction, and outcome.

\section{Study 1}

In Study 1, the comparison outcomes assessed by the SCR were feelings of status and solidarity, the comparison directions were similar versus dissimilar and better-off versus worse-off, and the situational variables were closeness of the target (friend/relative vs. acquaintance/stranger) and subjectivity and desirability of the target characteristic. "Subjectivity" is short for the perceived subjectivity of the basis for evaluating the characteristic. Subjective characteristics are those that are generally perceived as lacking any objective or commonly shared basis for evaluation. Examples of subjective characteristics would include attitudes, feelings, and personality because any ranking of those attributes is generally perceived as subjective. In contrast, objective characteristics are those that are perceived as having an objective or commonly shared basis for evaluation. Examples of objective characteristics would include academic standing, physical appearance, and wealth because most people prefer (and assume others also prefer) to have good grades, good looks, and a lot of money. To the extent that abilities and opinions are prototypical exemplars of the broader categories of objective and subjective attributes, this distinction can be traced back to the earliest writings on social comparison in which Festinger (1954) argued that abilities have "intrinsically different values" whereas opinions do not.

\section{Method}

Participants. Undergraduates (59 females, 47 males) participated for extra credit in psychology classes at the University of Idaho.

CSIV. The CSIV (Locke, 2000) is a 64-item self-report measure that assesses interpersonal values associated with each octant of a circular space defined by the orthogonal axes of status and solidarity (which the CSIV labels agency and communion). For each item, respondents indicate how important it is for them, on a scale from 0 (not important) to 4 (extremely important), that they act or appear or are treated that way in interpersonal situations. An example of an item assessing high agentic and low communal values is as follows:

When I am with him/her/them, it is . . $012234 \ldots$ that I am the one in charge.

An example of an item assessing high communal and low agentic values is as follows:

When I am with him/her/them, it is . . $0101234 \ldots$ that they approve of me.

The entire CSIV can be viewed at www.its.uidaho.edu/klocke/csiv_form .htm.

Locke (2000) showed that the scales have good internal consistency and test-retest reliability, a circumplex structure, and convergent and discrimi- 
nant validity in relation to interpersonal traits assessed by the Bem Sex Role Inventory (Bem, 1974), interpersonal goals assessed by the Interpersonal Goals Inventory (Dryer \& Horowitz, 1997), interpersonal problems assessed by the Inventory of Interpersonal Problems (Horowitz, Alden, Wiggins, \& Pincus, 2000), personality disorders assessed by the Millon Clinical Multiaxial Inventory-III (Millon, 1994), and implicit power and intimacy motives assessed by the Thematic Apperception Test (McAdams, 1992; Winter, 1992). Following Wiggins, Phillips, and Trapnell (1989), overall agency (A) and communion (C) scores were computed from the eight octant scales as follows: $\mathrm{A}=\Sigma S_{i} \sin \theta_{i}$ and $\mathrm{C}=\Sigma S_{i} \cos \theta_{i}$, where $S_{\mathrm{i}}$ is the $i$ th octant score, $\theta_{i}$ is the angle at the center of that octant, and the angles of the $+\mathrm{C}$ and $+\mathrm{A}$ octants were $0^{\circ}$ and $90^{\circ}$, respectively. As expected, across the three samples in this article, $\mathrm{A}$ and $\mathrm{C}$ scores were independent, $r(387)=-.09, n s$.

SCR. The first three questions assessed the situation. (1) "With whom did you compare yourself?" The response options were friend/relative and acquaintance/stranger. (2) "What was being compared?" The response options were academic skills/status, wealth and possessions, social/relationships, attitudes/feelings/opinions, physical appearance, other-personality, other-ability, and other. The responses were coded into two categories: objective characteristics (i.e., status, wealth, abilities, and looks) and subjective characteristics (i.e., relationships, attitudes, and personality). (3) "Was the characteristic of the other person (a) desirable, (b) undesirable, (c) neutral/neither?"

The remaining 12 questions were answered on scales ranging from 1 (not at all) to 7 (very much). Four questions assessed comparison direction: Specifically, to what extent during the comparison did the participant feel the target was "better off than you," "worse-off than you," "different from you," and "similar to you?" Ratings of better and worse were summed to create an overall vertical comparison score (with higher scores indicating higher status for the self); ratings of similar and different were summed to create an overall horizontal comparison score (with higher scores indicating greater similarity). Finally, eight questions assessed affect; specifically, to what extent during the comparison did the participant feel "confident," "connected," "bad about yourself," "a sense of isolation and separateness from them," "good about yourself," "distant," "insecure," and "a sense of solidarity and kinship with them?. To reduce the number of feeling scales, I computed the correlation coefficient between each pair of feelings for each participant. Subjecting the mean within-subjects coefficients to hierarchical cluster analysis (using Ward's method) revealed two distinct clusters of feelings. The items within each cluster were averaged to create two affect scales. The scale consisting of "confident" and "good about yourself" versus "insecure" and "bad about yourself" was called agentic feelings. The scale consisting of "connected" and "solidarity" versus "isolated" and "distant" was called communal feelings.

Procedure. Participants were given a packet containing the CSIV, 10 SCRs, and detailed instructions for completing and returning the SCRs. The instructions asked participants to complete a SCR "each time you notice yourself talking about or thinking about similarities and/or differences between yourself and another person or persons with respect to some characteristic." Participants completed the SCRs in 11.6 days on average $(S D=9.0)$. Pearson $r$ s computed between the participants' responses to the SCR variables and the number of days they took to complete the SCRs revealed no significant relationships.

\section{Results and Discussion}

Data analysis. The data involved multiple lower level observations (SCRs) nested within upper level units (participants). I was interested in sources of variation in comparison experiences both within and between the participants. The within-subjects sources of variation were the SCR variables. The between-subjects sources of variation were interpersonal values and gender. The data were analyzed using multilevel random coefficient modeling (Kenny,
Kashy, \& Bolger, 1998; Nezlek, 2001). The program HLM/2L (Bryk \& Raudenbush, 1992; Bryk, Raudenbush, \& Congdon, 1996) performed the computations. The categorical variables were dummy-coded as follows: gender (female $=0$, male $=1$ ), target (distant $=0$, close $=1$ ), characteristic (objective $=0$, subjective $=1$ ), and desirability (undesirable $=-1$, neutral $=0$, desirable $=1$ ). The continuous variables were standardized relative to their between-subjects means and standard deviations in order to facilitate interpretation of the regression coefficients.

Do interpersonal values and gender predict comparison experiences? First, I determined what proportion of the variance in comparison direction and affect was between subjects. To do so, I fit an unconditional model with no predictor variables for each outcome. The unconditional within-subjects model defines the outcome of a particular comparison as a function of participant $j$ 's mean outcome across all comparisons and a deviation from that mean, as shown in Equation 1:

$$
\mathrm{Y}_{\mathrm{ij}}=\beta_{0 \mathrm{j}}+r_{i j} .
$$

For example, if the outcome is agentic affect, $\mathrm{Y}_{\mathrm{ij}}$ is the agentic affect on participant $j$ 's $i$ th comparison, $\beta_{0 j}$ is $j$ 's mean agentic affect across all comparisons, and $r_{i j}$ is the residual component of agentic affect for record $i$. The unconditional between-subjects model defines $j$ 's mean outcome as a function of the average outcome across all participants and a deviation from that grand mean, as shown in Equation 2:

$$
\beta_{0 \mathrm{j}}=\gamma_{00}+u_{0 j}
$$

For example, if the outcome is agentic affect, $\beta_{0 j}$ is $j$ 's mean agentic affect, $\gamma_{0 o}$ is the agentic affect grand mean, and $u_{O j}$ is the residual component of agentic affect for $j$.

Therefore, the proportion of the variance in each outcome variable that was between subjects was the variance in $u_{O j}$ divided by the total variance. The percentage of variance between subjects was $7.3 \%$ for similarity, $12.3 \%$ for superiority, $27.1 \%$ for agentic feelings, and $7.2 \%$ for communal feelings (all $p s<.001$ ).

Because there was significant between-subjects variation in all outcomes, the next step was to model that between-subjects variation in terms of the between-subjects predictors (gender and agentic and communal values). To do so, Equation 2 was expanded as follows:

$$
\beta_{0 \mathrm{j}}=\gamma_{00}+\gamma_{01} \mathrm{G}_{\mathrm{j}}+\gamma_{02} \mathrm{~A}_{\mathrm{j}}+\gamma_{03} \mathrm{C}_{\mathrm{j}}+u_{0 j},
$$

where $G_{j}, A_{j}$ and $C_{j}$ are $j$ 's scores for gender, agentic values, and communal values, and $\gamma_{01}$ is the effect of $\mathrm{G}$ (controlling for the effects $\mathrm{A}$ and $\mathrm{C}$ ), $\gamma_{\mathrm{O} 2}$ is the effect of $\mathrm{A}$ (controlling for $\mathrm{G}$ and $\mathrm{C}$ ), and $\gamma_{03}$ is the effect of $\mathrm{C}$ (controlling for $\mathrm{G}$ and $\mathrm{A}$ ).

The results showed that males reported more agentic feelings than did females $(\gamma=0.302, S E=0.115, p<.01)$. Agentic values were associated positively with vertical comparisons $(\gamma=0.104$, $S E=0.046, p<.05)$ and negatively with horizontal comparisons $(\gamma=-0.130, S E=0.041, p<.01)$ and communal feelings $(\gamma=$ $-0.102, S E=0.041, p=.01)$. Horizontal comparisons appeared to mediate the relationship between agentic values and communal feelings. When each participant's mean horizontal comparison score was added to Equation 3, the scores strongly predicted communal feelings $(\gamma=0.488, S E=0.076, p<.001)$ and eliminated the effect of agentic values $(\gamma=-0.046, S E=0.036$, 
$p>.2)$. Surprisingly, communal values also predicted vertical comparisons $(\gamma=0.121, S E=0.046, p<.01)$ and agentic feelings $(\gamma=0.122, S E=0.058, p<.05)$. Vertical comparisons appeared to mediate the relationship between communal values and agentic feelings. When each participant's mean vertical comparison score was added to Equation 3, the scores strongly predicted agentic feelings $(\gamma=0.507, S E=0.115, p<.001)$ and eliminated the effect of communal values $(\gamma=0.011, S E=0.053$, $p>.5)$.

Do situational variables predict comparison experiences? Although there was significant between-subjects variance in comparison experiences, most of the variance was within subjects. In the preceding section I tested if individual differences (between subjects) could explain the between-subjects variance in comparison experiences. In this next section I tested if situational differences (within subjects) could explain the within-subjects variation in comparison experiences.

First, I tested the effects of the comparison situation (the target and the subjectivity and desirability of the characteristic). The percentage of comparisons with close (vs. distant) targets was $65.9 \%$. The percentage of comparisons involving subjective (vs. objective) characteristics was $41.7 \%$. The characteristic of the other person was undesirable in $30.9 \%$ of comparisons, desirable in $44.0 \%$, and neutral in $25.1 \%$. To test the effects of these predictors, Equation 1 was expanded as follows:

$$
\mathrm{Y}_{\mathrm{ij}}=\beta_{0 \mathrm{j}}+\beta_{1 \mathrm{j}} \mathrm{X}_{1 \mathrm{ij}}+\beta_{2 \mathrm{j}} \mathrm{X}_{2 \mathrm{ij}}+\beta_{3 \mathrm{j}} \mathrm{X}_{3 \mathrm{ij}}+r_{i j},
$$

where $\mathrm{X}_{1 \mathrm{ij}}, \mathrm{X}_{2 \mathrm{ij}}$, and $\mathrm{X}_{3 \mathrm{ij}}$ are the target, characteristic, and desirability, respectively, for participant $j$ 's $i$ th comparison, and $\beta_{1 \mathrm{j}}, \beta_{2 \mathrm{j}}$, $\beta_{3 j}$ are the target-outcome, characteristic-outcome, and contextoutcome slopes, respectively. Because I was testing withinsubjects effects, the predictors were centered around the mean for each participant. For example, $X_{1 \mathrm{ij}}$ is $j$ 's $i$ th comparison target dummy code ( 0 or 1$)$ minus $j$ 's average target dummy code.

Table 1 shows the results. Comparing with close (as opposed to distant) targets was associated positively with horizontal comparisons, communal feelings, and, to a weaker degree, agentic feelings. Comparing subjective (as opposed to objective) characteristics was associated positively with vertical comparisons. The desirability of the target's characteristic was associated positively with horizontal comparisons and communal feelings and nega- tively with vertical comparisons and agentic feelings. To explicate the effects of desirability, Table 2 shows the mean $\beta_{0 j}$ for each outcome variable at each level of desirability. Vertical comparisons and agentic feelings decrease as the target characteristic varies from undesirable to neutral to desirable (all $p \mathrm{~s}<.01$ ). Horizontal comparisons and communal feelings increase as the target characteristic varies from undesirable to neutral $(p s<.01)$ but remain unchanged as the target characteristic varies from neutral to desirable. Thus, desirability influences horizontal comparisons and communal feelings not because people feel especially similar and connected to desirable targets, but because they feel distinct and distant from undesirable ones.

Does comparison direction predict feelings? The effects of comparison direction on affect were tested as follows:

$$
\mathrm{Y}_{\mathrm{ij}}=\beta_{0 \mathrm{j}}+\beta_{1 \mathrm{j}} \mathrm{X}_{1 \mathrm{ij}}+\beta_{2 \mathrm{j}} \mathrm{X}_{2 \mathrm{ij}}+\mathrm{r}_{\mathrm{ij}},
$$

where $\mathrm{Y}_{\mathrm{ij}}$ is the affect on participants $j$ 's $i$ th comparison, $\mathrm{X}_{1 \mathrm{ij}}$ and $\mathrm{X}_{2 \mathrm{ij}}$ are the horizontal and vertical comparison scores, respectively, and $\beta_{1 \mathrm{j}}$ and $\beta_{2 \mathrm{j}}$ are the corresponding direction-affect slopes. Vertical comparisons predicted agentic feelings $(\beta=$ $0.512, S E=0.036, p<.001)$ but not communal feelings. Horizontal comparisons predicted communal feelings $(\beta=0.591$, $S E=0.031)$ and to a lesser extent agentic feelings $(\beta=0.143$, $S E=0.024$, both $p$ s $<.001)$. To understand why similarity predicted agentic feelings, I examined the relationship at each level of desirability. Horizontal comparisons and agentic feelings had a strong positive relationship when the characteristic was desirable $(\beta=0.338, S E=0.044, p<.001)$, a weak positive relationship when the characteristic was neutral $(\beta=0.162, S E=0.072, p<$ $.05)$, and a nonsignificant negative relationship when the characteristic was undesirable $(\beta=-0.064, S E=0.059)$. Thus, similarity enhanced confidence and esteem when the shared characteristic was desirable and not when it was undesirable. In contrast, similarity strongly predicted communal feelings regardless of the desirability of the characteristic being shared (all $\beta \mathrm{s}>.431, p \mathrm{~s}<$ $.001)$.

Do values or gender moderate the effects of comparison direction? The final question was whether there was significant between-subjects variance in the direction-affect slopes, and, if so, whether the between-subjects predictors (gender and values) could explain some of that variance. To determine if there was signifi-

Table 1

Effects of Target Closeness and Characteristic Subjectivity and Desirability on Comparison

\begin{tabular}{|c|c|c|c|c|c|c|}
\hline \multirow[b]{2}{*}{ Outcome } & \multicolumn{2}{|c|}{ Target } & \multicolumn{2}{|c|}{ Subjectivity } & \multicolumn{2}{|c|}{ Desirability } \\
\hline & $\beta$ & $S E$ & $\beta$ & $S E$ & $\beta$ & $S E$ \\
\hline \multicolumn{7}{|l|}{ Direction } \\
\hline Vertical & -0.030 & 0.051 & $0.124 *$ & 0.045 & $-0.720 * *$ & 0.040 \\
\hline Horizontal & $0.309 * *$ & 0.069 & 0.028 & 0.060 & $0.363^{* *}$ & 0.038 \\
\hline \multicolumn{7}{|l|}{ Feelings } \\
\hline Agentic & $0.153^{*}$ & 0.056 & 0.080 & 0.050 & $-0.415^{* *}$ & 0.039 \\
\hline Communal & $0.752 * *$ & 0.078 & 0.026 & 0.063 & $0.284 * *$ & 0.037 \\
\hline
\end{tabular}
Direction and Feelings

Note. The betas represent standard deviation change in the outcomes as a function of participant-centered variations in target (distant $=0$, close $=1$ ), subjectivity (objective characteristic $=0$, subjective characteristic $=$ 1 ), and desirability (undesirable $=-1$, neutral $=0$, desirable $=1$ ).

$* p<.05 . \quad * * p<.005$. 
Table 2

Comparison Direction and Affect as a Function of the Desirability of the Target Characteristic

\begin{tabular}{|c|c|c|c|c|c|c|}
\hline \multirow[b]{2}{*}{ Outcome } & \multicolumn{2}{|c|}{ Undesirable } & \multicolumn{2}{|c|}{ Neutral } & \multicolumn{2}{|c|}{ Desirable } \\
\hline & $\beta$ & $S E$ & $\beta$ & $S E$ & $\beta$ & $S E$ \\
\hline \multicolumn{7}{|l|}{ Direction } \\
\hline Vertical & 0.846 & 0.054 & 0.094 & 0.062 & -0.675 & 0.057 \\
\hline Horizontal & -0.556 & 0.050 & 0.321 & 0.060 & 0.234 & 0.062 \\
\hline \multicolumn{7}{|l|}{ Feelings } \\
\hline Agentic & 0.442 & 0.069 & 0.119 & 0.072 & -0.428 & 0.079 \\
\hline Communal & -0.464 & 0.062 & 0.226 & 0.064 & 0.205 & 0.062 \\
\hline
\end{tabular}

Note. The betas represent mean z-scores.

cant variance in slopes, the within-subjects level of the model was the same as Equation 5, and the between-subjects level was as follows:

$$
\begin{aligned}
& \beta_{1 \mathrm{j}}=\gamma_{10}+u_{1 j} \text { and } \\
& \beta_{2 \mathrm{j}}=\gamma_{20}+u_{2 j},
\end{aligned}
$$

where $\beta_{1 \mathrm{j}}$ and $\beta_{2 \mathrm{j}}$ are the horizontal and vertical direction-affect slopes, respectively, for participant $j, \gamma_{10}$ and $\gamma_{20}$ are the average slopes, and $u_{1 j}$ and $u_{2 j}$ are the components of the slopes unique to $j$.

There was significant between-subjects variance in two slopes: the vertical comparison-agentic feeling slope and the horizontal comparison-communal feeling slope. To test whether gender or values explained some of the variance in these slopes, I expanded Equation 6 and 7 as follows:

$$
\begin{aligned}
& \beta_{1 j}=\gamma_{10}+\gamma_{11} \mathrm{G}_{j}+\gamma_{12} \mathrm{~A}_{\mathrm{j}}+\gamma_{13} \mathrm{C}_{\mathrm{j}}+u_{1 j} \text { and } \\
& \beta_{2 \mathrm{j}}=\gamma_{20}+\gamma_{21} \mathrm{G}_{\mathrm{j}}+\gamma_{22} \mathrm{~A}_{\mathrm{j}}+\gamma_{23} \mathrm{C}_{\mathrm{j}}+u_{2 j},
\end{aligned}
$$

where $\mathrm{G}_{\mathrm{j}}, \mathrm{A}_{\mathrm{j}}$ and $\mathrm{C}_{\mathrm{j}}$ are $j$ 's scores for gender, agentic values, and communal values, respectively. Only one effect was significant: Communal values moderated the relationship between horizontal comparisons and communal feelings $(\gamma=0.066, S E=0.032, p<$ $.05)$. The effect of horizontal comparisons on communal feelings was greater for people who placed greater value on communion.

To summarize the key results, Study 1 found a clear relationship between horizontal comparisons and communal feelings, and this relationship was stronger for people who placed more value on solidarity. There was also a clear relationship between vertical comparisons and agentic feelings, but this relationship was not stronger for people who placed more value on status. When the characteristic of the target was desirable, people tended to make connective comparisons, and noticing these shared virtues enhanced not only communal feelings but also agentic feelings. In contrast, when the characteristic was undesirable, people tended to emphasize their differences and, concomitantly, their relative status.

\section{Study 2}

Whereas Study 1 concerned the effects of comparison direction on feelings related to status and solidarity, Study 2 concerned the effects of comparison direction on whether comparisons are experienced as helpful and as improving overall well-being. Because the importance of specific feelings varies across persons and situations, they are indirect predictors of whether a comparison will help or comfort a particular person at a particular time. Therefore, instead of asking about specific feelings, Study 2 asked participants directly whether each comparison was helpful and mood-enhancing overall. There were also a few other minor differences between Study 2 and Study 1. First, to explore the role of the interpersonal context, Study 2 participants recorded whether the comparison was made during an interaction (instead of recording the desirability of the characteristic). Second, Study 2 used bipolar scales (instead of unipolar scales) to assess comparison direction. Third, Study 2 participants completed 15 SCRs (instead of only 10).

\section{Method}

Participants. Undergraduates (73 females, 36 males) whose ages ranged from 18 to 45 years $(M=21.0$ years, $S D=3.4)$ participated for extra credit in psychology classes at the University of Idaho.

SCR. The first three items assessed the situation. (1) "With whom did you compare yourself?" The response options were friend/relative and acquaintance/stranger. (2) "What type of social contact was involved?" The response options were "interaction" and "no interaction (just saw or thought about the person)." (3) "What was being compared? The response options were academic/work performance or status, wealth and possessions, skills and abilities, social relationships, attitudes/feelings/opinions, personality or personal/interpersonal style, physical appearance, and other. The responses were coded into two categories: objective characteristics (i.e., status, wealth, skills, and looks) and subjective characteristics (i.e., relationships, attitudes, and personality).

The next two items assessed comparison direction. (4) "Did you feel similar to or different from him/her/them with respect to this characteristic?" The response options ranged from -3 (very much different) to +3 (very much similar). (5) "Did you feel better off or worse off than him/her/them with respect to this characteristic?" The response options ranged from -3 (very much worse off) to +3 (very much better off). The final two items assessed the overall immediate impact. (6) "Did you find this comparison helpful or harmful to you?" The response options ranged from -3 (very much harmful) to +3 (very much helpful). (7) "Overall, did this comparison make you feel better or worse?" The response options ranged from -3 (very much worse) to +3 (very much better).

Procedure. The procedure was identical to Study 1 except that participants were required to complete 15 SCRs. Participants completed the SCRs in 11.0 days on average $(S D=9.9)$. As in Study 1 , Pearson $r$ s were computed between the days taken to complete the SCRs and each participant's mean response to each SCR variable. Whereas Study 1 found no significant correlations, Study 2 (perhaps because it involved completing $50 \%$ more SCRs) found that people who made more contrastive and less 
mood-enhancing comparisons tended to make comparisons less frequently, $r(107)=-.23$ and -.26 , respectively, $p$ s $<.05$.

\section{Results and Discussion}

The data were analyzed using the same procedures as in Study 1 . The within-subjects sources of variation were the SCR variables. The between-subjects sources of variation were interpersonal values and gender. The categorical variables were dummy-coded as follows: gender (female $=0$, male $=1$ ), target $($ distant $=0$, close $=1$ ), subjectivity (objective $=0$, subjective $=1$ ), context (no interaction $=0$, interaction $=1$ ). The continuous variables were standardized relative to their between-subjects means and standard deviations.

Do interpersonal values and gender predict comparison experiences? First, I used the procedure detailed in Study 1 (see Equations 1 and 2) to test if there was significant variation in participants' comparison experiences. The between-subjects variance was $10.5 \%$ for horizontal comparisons, $7.2 \%$ for vertical comparisons, $9.6 \%$ for perceived helpfulness, and $9.0 \%$ for affect change (all $p \mathrm{~s}<.001$ ). Therefore, I used the procedure detailed in Study 1 (see Equation 3 ) to model the between-subjects variation in comparisons experiences in terms of the between-subjects predictors (gender and interpersonal values).

There were three significant findings. First, males rated the helpfulness of the comparisons higher than did females $(\gamma=0.203, S E=0.082, p<.05)$. Second, agentic values predicted higher vertical comparisons (rating the self as better off; $\gamma=0.073, S E=0.035, p<.05)$. Third, agentic values predicted feeling better following the comparison $(\gamma=0.103, S E=0.036$, $p<.005)$. Vertical comparisons appeared to mediate the relationship between agentic values and affect change. When each participant's mean vertical comparison score was added to Equation 3, the scores strongly predicted feeling better $(\gamma=0.277$, $S E=0.025, p<.001)$ whereas the effect of agentic values was only marginally significant $(\gamma=0.048, S E=0.025, p<.06)$. Thus, agentic values may predict feeling better after comparisons in part because they predispose people to judge themselves superior to the target.

Do situational variables predict comparison experiences? Although there was between-subjects variance in comparison experiences, on average over $90 \%$ of the variance was within subjects. In this section I seek to explain the variance within participants.
First, I tested the effects of the comparison situation (target, context, and subjectivity). The percentage of comparisons with close (vs. distant) targets was $65.6 \%$; the percentage made during (vs. not during) interactions was $53.8 \%$; and the percentage involving subjective (vs. objective) topics was $45.4 \%$. To test the effects of these predictors, Equation 1 was expanded as follows:

$$
\mathrm{Y}_{\mathrm{ij}}=\beta_{0 \mathrm{j}}+\beta_{1 \mathrm{j}} \mathrm{X}_{1 \mathrm{ij}}+\beta_{2 \mathrm{j}} \mathrm{X}_{2 \mathrm{ij}}+\beta_{3 \mathrm{j}} \mathrm{X}_{3 \mathrm{ij}}+r_{i j},
$$

where $X_{1 \mathrm{ij}}, \mathrm{X}_{2 \mathrm{ij}}$, and $\mathrm{X}_{3 \mathrm{ij}}$ are the target, subjectivity, and context, respectively, for participant $j$ 's $i$ th comparison. As in Study 1, the predictors were centered within participants. Table 3 shows the results. Comparisons made with close others or during interactions were associated with more connective horizontal comparisons. Comparisons made during interactions or involving subjective characteristics were associated with more downward comparisons and were more likely to be described as helpful and as making one feel better.

Does comparison direction predict comparison outcomes? Next, I tested the effects of comparison direction on comparison outcomes (perceived helpfulness and affect change) using the procedure detailed in Study 1 (see Equation 5). There were positive relationships between both vertical and horizontal comparisons and ratings of helpfulness $(\beta=0.437, S E=0.036$, and $\beta=0.135, S E=0.023$, respectively) and feeling better $(\beta=0.595, S E=0.032$, and $\beta=0.164, S E=0.023$, respectively; all $p \mathrm{~s}<.001)$. Thus, comparisons that involved downward as opposed to upward comparisons or connective as opposed to contrastive comparisons were more likely to be perceived as helpful and as improving mood.

Do values or gender moderate the effects of comparison direction? To test whether the between-subjects predictors (gender and values) can explain between-subjects variation in the direction-outcome slopes, I used the procedure detailed in Study 1 (see Equations 6-9). There was significant variance in all four direction-outcome slopes. Table 4 shows that communal values predicted all four slopes whereas agentic values predicted none. Communal values predicted weaker effects of vertical comparisons and stronger effects of horizontal comparisons on ratings of affect and helpfulness. Finally, the effects of vertical comparisons on ratings of affect and helpfulness were stronger for females than for males. Of interest, another study of naturalistic social comparison also found the effects of upward and downward comparisons

Table 3

Effects of Comparison Target, Subjectivity of Content, and Context on Comparison Outcomes

\begin{tabular}{|c|c|c|c|c|c|c|}
\hline \multirow[b]{2}{*}{ Outcome } & \multicolumn{2}{|c|}{ Target } & \multicolumn{2}{|c|}{ Subjectivity } & \multicolumn{2}{|c|}{ Context } \\
\hline & $\beta$ & $S E$ & $\beta$ & $S E$ & $\beta$ & $S E$ \\
\hline \multicolumn{7}{|l|}{ Direction } \\
\hline Vertical & -0.057 & 0.057 & $0.390 * *$ & 0.060 & $0.148 *$ & 0.065 \\
\hline Horizontal & $0.223 * *$ & 0.063 & 0.082 & 0.050 & $0.137 *$ & 0.059 \\
\hline Feeling better & -0.044 & 0.056 & $0.272 * *$ & 0.056 & $0.172 *$ & 0.055 \\
\hline Helpfulness & -0.006 & 0.059 & $0.164 * *$ & 0.058 & $0.240 * *$ & 0.060 \\
\hline
\end{tabular}

Note. The betas represent standard deviation change in the outcomes as a function of participant-centered variations in target (distant $=0$, close $=1$ ), subjectivity (objective characteristic $=0$, subjective characteristic $=$ 1 ), and context (no interaction $=0$, interaction $=1$ ).

$* p<.05$. $* * p<.005$. 
Table 4

Effects of Gender and Interpersonal Values on Direction-Outcome Slopes

\begin{tabular}{|c|c|c|c|c|c|c|}
\hline \multirow[b]{2}{*}{ Slope } & \multicolumn{2}{|c|}{ Agentic values } & \multicolumn{2}{|c|}{ Communal values } & \multicolumn{2}{|c|}{ Gender } \\
\hline & $\gamma$ & $S E$ & $\gamma$ & $S E$ & $\gamma$ & $S E$ \\
\hline Vertical—feel better & 0.051 & 0.030 & $-0.105^{* *}$ & 0.031 & $-0.249^{* *}$ & 0.066 \\
\hline Vertical—helpful & -0.003 & 0.035 & $-0.073 *$ & 0.036 & $-0.261 * *$ & 0.077 \\
\hline Horizontal-feel better & -0.010 & 0.023 & $0.069 * *$ & 0.023 & 0.031 & 0.049 \\
\hline Horizontal-helpful & 0.011 & 0.023 & $0.068 * *$ & 0.023 & 0.075 & 0.048 \\
\hline
\end{tabular}

Note. The dummy codes for gender were female $=0$ and male $=1$.

$* p<.05$. ** $p<.005$.

on postcomparison mood to be stronger for females than for males (Giordano et al., 2000). However, this effect was not even marginally significant in Study 1, suggesting that it might be sensitive to how the questions are asked.

To summarize the key results, Study 2 found that both solidarity-enhancing horizontal comparisons and status-enhancing vertical comparisons were experienced as mood-enhancing and helpful. The more people valued solidarity, the more they were affected by horizontal comparisons and the less they were affected by vertical comparisons (the latter perhaps because issues related to solidarity explained a greater proportion of the variance in their judgments).

\section{Study 3}

Study 3 differed from Studies 1 and 2 in three ways. First, whereas Studies 1 and 2 required participants to record a specific number of comparisons, Study 3 asked participants to record only as many comparisons as they spontaneously noticed over the course of 1 week. Second, in addition to assessing agentic and communal feelings (as in Study 1), Study 3 also assessed general feelings of happiness. Third, whereas Studies 1 and 2 used continuous rating scales to assess comparison direction (highlighting how status and solidarity can vary in an independent and continuous fashion), Study 3 used a multiple-choice format in which participants picked which direction best fit their experience during the comparison (thus highlighting how each of the four directions can define a comparison experience and have distinct consequences).

\section{Method}

Participants. Undergraduates (107 females, 82 males, 2 unknown) participated for extra credit in psychology classes at the University of Idaho.

SCR. The first two items assessed the situation. (1) "With whom did you compare yourself?" The response options were "friend" or "relative" and "acquaintance" or "stranger." (2) "What type of social contact was involved?" The response options were "interaction" and "no interaction (just saw or thought about the person)."

The third item assessed comparison direction by asking participants to complete the sentence "While comparing this characteristic I was thinking that..." by circling either (a) we did not share this characteristic in common, (b) we shared this characteristic in common, (c) with respect to this characteristic, I was better-off, or (d) with respect to this characteristic, I was worse-off.
Finally, participants rated how they were feeling after the comparison on 1 to 7 scales whose end-points were labeled: alienated-intimate, confident-insecure, connected-isolated, disadvantaged-advantaged, distant-close, gloomy-cheerful, happy-sad, included-excluded, inferiorsuperior, peaceful-worried, powerless-powerful, tense-calm, worthyworthless. To reduce the number of feeling scales, I computed the correlation coefficient between each pair of feelings for each participant. Hierarchical cluster analysis (using Ward's method) on the mean withinsubjects coefficients revealed three coherent clusters of feelings. The items within each group were averaged to create three affect scales. The scale consisting of close, connected, intimate, and included was called communal feelings. The scale consisting of confident, advantaged, superior, and worthy was called agentic feelings. The scale consisting of happy, calm, peaceful, and cheerful was called happy feelings.

Procedure. The CSIV was administered in small groups. Then, the packet of records was distributed with the following instructions: "Over the next week, each time you notice yourself talking or thinking about similarities or differences between yourself and another person or persons with respect to some characteristic, fill out one of the attached Social Comparison Record sheets ... We have given you 20 record sheets. It is fine for you to finish all 20 within a few days, and it is fine for you to not finish all 20 by the end of the seven days..." Ninety-one percent of the participants (96 females, 78 males), whose ages ranged from 18 to 37 years ( $M=19.7$ years, $S D=2.9)$, returned their SCRs. The mean number of records completed was $9.9(S D=5.1)$. Pearson $r$ s were computed between the number of SCRs completed and each participant's mean response to each SCR variable. The number of comparisons completed was positively related to connective comparisons, $r(172)=.19$, and happy feelings, $r(172)=.16$, and inversely related to upward comparisons, $r(172)=-.16$ (all $p$ s $<.05$ ). Thus, just as the Study 2 participants who made more connective and mood-enhancing comparisons took less time to complete a fixed number of SCRs, the Study 3 participants whose comparisons tended to enhance solidarity and happiness (without lowering status) reported more comparisons during a fixed period of time. These results suggest that people whose comparisons tend to be distancing or deflating comparisons may tend to avoid — or at least avoid thinking about and reporting — social comparisons.

\section{Results and Discussion}

Data analytic strategy. The data were analyzed using the same procedures as in Study 1. The within-subjects sources of variation were the SCR variables. The between-subjects sources of variation were interpersonal values and gender. The categorical variables were dummy-coded as follows: gender (female $=0$, male $=1$ ), target $($ distant $=0$, close $=1)$, context (no interaction $=0$, interaction $=1$ ), and the four directions (occurrence $=1$, nonoc- 
currence $=0$ ). The continuous variables were standardized relative to their between-subjects means and standard deviations.

Do interpersonal values and gender predict comparison experiences? The procedure detailed in Study 1 (see Equations 1 and 2) showed that a significant proportion of the variance in all comparison experiences was between subjects $(p s<.001)$. The between-subjects variance was $12.73 \%, 8.54 \%, 8.54 \%$, and $12.67 \%$, respectively, for upward, downward, connective, and contrastive comparisons; and $8.98 \%, 7.07 \%$, and $9.46 \%$, respectively, for agentic, communal, and happy feelings. The between-subjects variance in comparisons experiences was then modeled as a function of the between-subjects predictors (gender and interpersonal values), as detailed in Study 1 (see Equation 3). The only significant effects were that males reported higher levels of agentic $(\gamma=0.215, S E=0.068)$, communal $(\gamma=0.142, S E=0.067)$, and happy $(\gamma=0.257, S E=0.068)$ feelings following social comparisons $(p s<.05)$. There were no main effects of interpersonal values.

Does comparison target, context, or direction predict comparison experiences? Although there was between-subjects variance, on average over $90 \%$ was within subjects. In this section I seek to explain the variance within participants. First, I tested the effects of target and context on comparison direction and affect by expanding Equation 1 as follows:

$$
\mathrm{Y}_{\mathrm{ij}}=\beta_{0 \mathrm{j}}+\beta_{1 \mathrm{j}} \mathrm{X}_{1 \mathrm{ij}}+\beta_{2 \mathrm{j}} \mathrm{X}_{2 \mathrm{ij}}+r_{i j},
$$

where $X_{1 \mathrm{ij}}$ and $\mathrm{X}_{2 \mathrm{ij}}$ are the target and context for participant $j$ 's $i$ th comparison. The predictors were centered within participants. The percentage of comparisons with close targets was $58.5 \%$, and the percentage made during interactions was $48.2 \%$. Comparing with a close target predicted communal feelings $(\beta=0.162$, $S E=0.059, p<.01)$. Comparing during interactions predicted fewer upward comparisons $(\beta=-0.052, S E=0.024, p<.05)$, and more shared comparisons $(\beta=0.074, S E=0.021, p=.001)$, more agentic feelings $(\beta=0.182, S E=0.056, p=.001)$, more communal feelings $(\beta=0.235, S E=0.054, p<.001)$, and more happy feelings $(\beta=0.145, S E=0.065, p<.05)$.

Does comparison direction predict comparison outcomes? Next, I tested the effects of comparison direction on affect. Every direction occurred with some frequency: $24.9 \%$ of comparisons were upward, $25.8 \%$ were downward, $32.3 \%$ were contrastive, and $17.0 \%$ were connective. That upward comparisons were as common as downward comparisons is surprising because previous studies of naturalistic social comparisons have found downward comparisons to be more common (Locke \& Nekich, 2000; Wheeler \& Miyake, 1992). However, those studies had participants make ratings on ordinal scales ranging from better-off to worse-off, whereas the current study had participants endorse one of four categories. In any case, because they were mutually exclusive categories, the effect of each direction was tested separately. As Table 5 shows, all of the slopes were significant. Upward and contrastive comparisons predicted more negative feelings; downward and connective comparisons predicted more positive feelings.

Do values or gender moderate the effects of comparison direction? To test whether the between-subjects predictors (gender and values) can explain between-subjects variation in directionaffect slopes, I used the procedure detailed in Study 1 (Equations 6-9). There was significant variance in five direction-affect slopes: upward-agentic, upward-happy, downward-agentic, connective-communal, and connective-happy. In accord with my previous findings, communal values predicted stronger positive relationships between connective comparisons and communal feelings $(\gamma=0.169, S E=0.087, p=.05)$, and between connective comparisons and happy feelings $(\gamma=0.170, S E=0.081, p<.05)$. Agentic values predicted less negative relationships between upward comparisons and agentic feelings $(\gamma=0.133, S E=0.060$, $p<.05)$, and between upward comparisons and happy feelings $(\gamma=0.154, S E=0.068, p<.05)$. That is, the more people endorsed agentic values, the less upward comparisons dampened their moods.

To summarize the key results, Study 3 found that connective comparisons raised and contrastive comparisons lowered affect, especially communal feelings. Downward comparisons raised and upward comparisons lowered affect, especially agentic feelings. As expected, the effects of connective comparisons on communal and happy feelings were stronger for people who placed more value on solidarity. In contrast, the effects of upward comparisons on agentic and happy feelings were weaker for people who placed more value on status.

\section{General Discussion}

Across all three studies, downward comparisons and connective comparisons were experienced as more helpful and more mood enhancing than were upward comparisons and contrastive com-

Table 5

Effects of Downward, Upward, Connective, and Contrastive Comparisons on Agentic, Communal, and Happy Feelings

\begin{tabular}{|c|c|c|c|c|c|c|}
\hline \multirow[b]{2}{*}{ Direction } & \multicolumn{2}{|c|}{ Communal } & \multicolumn{2}{|c|}{ Agentic } & \multicolumn{2}{|c|}{ Happy } \\
\hline & $\beta$ & $S E$ & $\beta$ & $S E$ & $\beta$ & $S E$ \\
\hline Downward & $0.243 * *$ & 0.057 & $1.033 * *$ & 0.060 & $0.652 * *$ & 0.068 \\
\hline Upward & $-0.621 * *$ & 0.054 & $-1.131 * *$ & 0.059 & $-0.863^{* *}$ & 0.053 \\
\hline Connective & $1.078 * *$ & 0.078 & $0.388^{* *}$ & 0.067 & $0.737 * *$ & 0.072 \\
\hline Contrastive & $-0.355^{* *}$ & 0.055 & $-0.143^{*}$ & 0.057 & $-0.276^{* *}$ & 0.057 \\
\hline
\end{tabular}

Note. The betas represent standard deviation change in the outcomes as a function of participant-centered variations in the predictors.

$* p<.05$. $* * p<.005$. 
parisons. Although every direction of comparison influenced every type of feeling in at least one study, the strongest and most consistent effects of vertical comparisons were on feelings of status and the strongest and most consistent effects of horizontal comparisons were on feelings of solidarity. Overall, the effects of comparison direction were in accord with the hypotheses and with the results of previous research.

The implications of similarity for feelings of status depended on the desirability of the characteristic. Similarity enhanced solidarity regardless of the characteristic, but only enhanced status to the extent that the characteristic was desirable. If misery loves miserable company, it is because such company provides solidarity, not status. What enhances confidence and esteem is perceiving oneself to be not just among others, but "among the better ones" (Collins, 2000).

Although most studies (including the present ones) have found downward comparisons enhancing and upward comparisons deflating, some studies have shown the opposite. However, typically in those studies, participants were simply exposed to targets or target characteristics prior to making judgments about the self and may have never consciously compared the self and the target (e.g., Dijksterhuis et al., 1998; Lockwood \& Kunda, 1997; Mussweiler \& Bodenhausen, 2002; Stapel \& Koomen, 2000, 2001). When the comparison is explicit and the target is distinct, contrast rather than assimilation predominates.

Although I did not predict any main effects of values, one reliable main effect did appear: Agentic values predicted higher self-ratings on the vertical comparison dimension. This finding is in accord with previous findings showing associations between downward comparisons and traits that are likely to be associated with agentic values such as self-esteem, dominance, and extraversion (for a review, see Wheeler, 2000).

The key hypotheses concerned the interaction of values and direction. I hypothesized that communal values would amplify the influence of horizontal comparisons and that agentic values would amplify the influence of vertical comparisons. The results supported the first hypothesis but not the second.

Across all studies, communal values magnified the influence of horizontal comparisons. Specifically, communal values magnified the effect of horizontal comparisons on communal feelings in Study 1 and on ratings of helpfulness and mood improvement in Study 2, and magnified the effect of connective comparisons on happy and communal feelings in Study 3. Study 3 revealed an interesting asymmetry: Communal values magnified the positive effects of connective comparisons but not the negative effects of contrastive comparisons. I actually anticipated this because values generally appear to be more consistent in magnifying positive than negative reactions (e.g., Cantor et al., 1991). Measures of values may predict positive reactions better because they typically frame values in positive, discrepancy-reducing, promotion-focused terms (Carver, Sutton, \& Scheier, 2000)—that is, they ask about wishes rather than fears. In contrast to measures of values, measures of dependency and self-criticism assess "depressive vulnerabilities" or sensitivities to not getting what you want; and these measures have been shown to predict the impact of upward comparisons on negative moods, at least when the topic pertains to the domain of vulnerability and there is some preexisting level of dysphoria (Giordano et al., 2000).
Communal values also predicted weaker effects of vertical comparisons on perceived helpfulness and mood enhancement. This interesting finding suggests that communal values may be associated with placing both more importance on horizontal comparisons and less importance on vertical comparisons. However, the effect may be limited to specific types of judgments as it was only found in Study 2 (which explicitly asked whether the comparison was helpful and made you feel better).

Agentic values did not magnify the effects of vertical comparisons. Indeed, in Study 3, agentic values predicted weaker relationships between upward comparisons and feelings of insecurity and unhappiness. Perhaps people with agentic values are less bothered by upward comparisons because they are confident that either they are already in the same class as the upward comparison targets-what Collins (1996, 2000) called "upward assimilation"or it is within their control to get there. Agentic values may also predict the use of a variety of other self-esteem regulation strategies (Tesser, 2000)—such as minimizing the relevance of the comparison dimension or affirming the self on another dimension-that can soften the impact of upward comparisons.

The current studies also provided some interesting information about the circumstances under which comparisons occurred. Across the studies, the percentage of comparisons with close (vs. distant) targets was $63 \%$, the percentage with subjective (vs. objective) content was $44 \%$, and the percentage during (vs. not during) interactions was $51 \%$. Thus, many comparisons occurred in each type of situation. The different situations were associated with different social comparison experiences. Comparing with close targets predicted perceiving greater similarity and feeling more positive. Comparing subjective topics predicted perceiving the self as relatively well-off and the comparison as helpful. Comparing during interactions predicted making more connective and fewer upward comparisons, feeling more positive, and perceiving the comparison as helpful. Conversely, comparisons of objective characteristics (such as wealth and physical appearance) with distant others or in the absence of interaction were more likely to be associated with feeling low and alienated and with judging the comparison to be unhelpful. Previous research on these situational variables yielded similar conclusions (Locke \& Nekich, 2000).

The effects of desirability were more complicated. The effects of desirability on agentic feelings differed from its effects on communal feelings. People tended to feel the most confident and the least connected when the target characteristic was undesirable. Thus, comparisons that increase feelings of agency may sometimes also have the consequence of increasing feelings of distance and alienation. When the target characteristic was desirable, people tended to feel less confident but no more connected than when the characteristic was neutral. Thus, both neutral and desirable targets tend to evoke feelings of connection, but neutral targets are less likely than desirable targets to simultaneously evoke feelings of insecurity.

Overall, the results do not convey the impression that people are actively choosing or construing comparisons in order to feel good. For example, as just noted, the neutral target characteristics were less likely to evoke insecurity (but no less likely to evoke connection) than were desirable characteristics. Yet, people were more likely to compare themselves with desirable target characteristics. As another example, people generally feel better when they make 
downward or connective comparisons. Yet, they made upward comparisons as often as downward comparisons, and made contrastive comparisons more often than connective comparisons. People also found comparisons involving subjective characteristics more helpful than those involving objective characteristics. Yet, the majority of comparisons involved objective characteristics. How can we make sense of these choices?

Perhaps one reason why many comparison choices seem to make no sense is that in fact many comparisons are not choices. Instead, they happen automatically. The current studies did not examine intentions directly, but in a similar study participants judged $32 \%$ of their comparisons to be "unintended" (Wood et al., 2000). Unintended comparisons are probably shaped not top-down by individuals' conscious goals and outcome expectancies, but instead bottom-up by the characteristics encountered and noticed in the course of everyday life. For example, very desirable and undesirable characteristics (such as very beautiful or very deformed bodies) may attract attention for reasons unrelated to social comparison, but once the characteristic is noticed, a comparison with the self may occur automatically.

In addition, even when an individual chooses a comparison, the choice will make no sense unless we understand that individual's motives, and there are many possible motives. In addition to wanting to enhance happiness, status, and solidarity, individuals may also want to evaluate themselves (Festinger, 1954), to improve themselves or be inspired (Taylor \& Lobel, 1989), to demarcate the range of performance (Wheeler et al., 1969), or predict their own future performance (Wheeler, Martin, \& Suls, 1997), and so on. Of course, an individual may want to meet many objectives at once, which may not always be possible. For example, it appears that target characteristics that maximize feelings of status (namely, undesirable characteristics) also tend to undermine feelings of solidarity. The self-esteem maintenance model (Tesser, 1988) highlights some strategies people can use to maintain both status (e.g., perceived superiority in relevant domains) and solidarity (e.g., closeness to important others). For example, members of a couple may learn to stake their status on different performance domains so as to avoid competition that might damage their solidarity (Beach \& Tesser, 1993). Nonetheless, because comparisons are composed of many interdependent facets, trade-offs cannot always be avoided. For example, once the characteristic and target are chosen, there may be little choice over the comparison direction. Choosing a different, more preferable direction may require choosing a different, less preferable target. The frequency of forced comparisons, and the difficulty of shaping even comparisons that are chosen, make it less surprising that people sometimes make comparisons that seem at first glance counterproductive.

\section{Limitations and Conclusions}

I will not discuss the strengths and limitations of SCRs in detail here, as that has been done elsewhere (Wheeler \& Miyake, 1992; Wood, 1996). Briefly, however, the key strength of eventcontingent record keeping is the ability to obtain information about what occurs in naturalistic settings close in time to the actual occurrences. The key limitation is that information is only obtained on the sample of events that participants notice and select to report. The key question, therefore, is whether the recorded events are representative of the population of naturalistic events. Although there is no reason to believe the sample of comparisons obtained from SCRs is biased in any systematic way, it is important to remain mindful of the possibility.

Future research should also consider the wider situational, relational, and cultural contexts in which social comparisons occur. The meaning and importance of status and solidarity is likely to vary with such factors as whether the situation is competitive versus cooperative, whether the relationship with the target is transient versus ongoing, and whether the broader culture is relatively collectivistic versus individualistic. For example, people from collectivistic cultures may react more negatively to contrastive and downward comparisons with in-group members and so be more reluctant to notice or express information that might contribute to such comparisons.

In conclusion, the current studies of college students' everyday comparisons showed that vertical and horizontal comparisons have strong and consistent effects on feelings of status and solidarity, respectively, and that communal values magnify the effects of connective comparisons. The meaning of social comparisons therefore came not only from the relationship between personal characteristics and relevant standards of comparison, but also from the relationship between the comparison information and relevant personal standards and values.

The causes and effects of social comparison are as variegated and tangled as the fabric of social life in which it is embedded. Projecting social comparison onto the axes of status and solidarity will of course fail to reveal the many implications of social comparison for values and experiences unrelated to status and solidarity. However, these two axes (and their cardinal pointsabove, below, together, and apart) can provide a simple but powerful framework for understanding the implications of social comparison for how individuals position themselves in relation to other individuals.

\section{References}

Alden, L. E., \& Phillips, N. (1990). An interpersonal analysis of social anxiety and depression. Cognitive Therapy and Research, 14, 499-512.

American Psychiatric Association. (1987). Diagnostic and statistical manual of mental disorders (3rd ed., rev.). Washington, DC: Author.

Bakan, D. (1966). The duality of human existence: Isolation and communion in Western man. Boston: Beacon Press.

Beach, S. R., \& Tesser, A. (1993). Decision making power and marital satisfaction: A self-evaluation maintenance perspective. Journal of Social and Clinical Psychology, 12, 471-494.

Beck, A. T. (1983). Cognitive therapy of depression: New perspectives. In P. Clayton \& J. Barrett (Eds.), Treatment of depression: Old controversies and new approaches (pp. 265-290). New York: Raven Press.

Bem, S. L. (1974). The measurement of psychological androgyny. Journal of Counseling and Clinical Psychology, 42, 155-162.

Bieling, P. J., \& Alden, L. E. (2001). Sociotropy, autonomy, and the interpersonal model of depression: An integration. Cognitive Therapy \& Research, 25, 167-184.

Blatt, S. J., D'Afflitti, J. P., \& Quinlan, D. M. (1976). Experiences of depression in normal young adults. Journal of Abnormal Psychology, 85, 383-389.

Bradlee, P. M., \& Emmons, R. A. (1992). Locating narcissism within the interpersonal circumplex and the Five-Factor model. Personality and Individual Differences, 13, 821-830.

Brewer, M. B., \& Weber, J. G. (1994). Self-evaluation effects of interpersonal versus intergroup social comparison. Journal of Personality and Social Psychology, 66, 268-275. 
Brown, J. D., Novick, N. J., Lord, K. A., \& Richards, J. M. (1992). When Gulliver travels: Social context, psychological closeness, and selfappraisals. Journal of Personality and Social Psychology, 62, 717-727.

Brown, R. (1965). Social psychology. New York: Free Press.

Bryk, A. S., \& Raudenbush, S. W. (1992). Hierarchical linear models: Applications and data analysis methods. Newbury Park, CA: Sage.

Bryk, A. S., Raudenbush, S. W., \& Congdon, R. T. (1996). Hierarchical linear modeling with the $H L M / 2 L$ and $H L M / 3 L$ programs. Chicago: Scientific Software.

Byrne, D. (1971). The attraction paradigm. New York: Academic Press.

Byrne, D., Griffitt, W., \& Stefaniak, D. (1967). Attraction and similarity of personality characteristics. Journal of Personality and Social Psychology, 5, 82-90.

Cantor, N., Norem, J., Langston, C., Zirkle, S., Fleeson, W., \& CookFlannagan, C. (1991). Life tasks and daily life experience. Journal of Personality, 59, 425-451.

Carli, L. L., Ganley, R., \& Pierce-Otay, A. (1991). Similarity and satisfaction in roommate relationships. Personality and Social Psychology Bulletin, 17, 419-426.

Carson, R. C. (1969). Interaction concepts of personality. Chicago: Aldine.

Carver, C. S., Sutton, S. K., \& Scheier, M. F. (2000). Action, emotion, and personality: emerging conceptual integration. Personality \& Social Psychology Bulletin, 26, 741-751.

Collins, R. L. (1996). For better or worse: The impact of upward social comparison on self-evaluations. Psychological Bulletin, 119, 51-69.

Collins, R. L. (2000). Among the better ones: Upward assimilation in social comparison. In J. Suls \& L. Wheeler (Eds.), Handbook of social comparison: Theory and research (pp. 159-171). New York: Plenum Press.

Conte, H. R., \& Plutchik, R. (1981). A circumplex model for interpersonal personality traits. Journal of Personality and Social Psychology, 40, 701-711.

Dijksterhuis, A., Spears, R., Postmes, T., Stapel, D. A., Koomen, W., van Knippenberg, A., \& Scheepers, D. (1998). Seeing one thing and doing another: Contrast effects in automatic behavior. Journal of Personality and Social Psychology, 75, 862-871.

Dryer, D. C., \& Horowitz, L. M. (1997). When do opposites attract? Interpersonal complementarity versus similarity. Journal of Personality and Social Psychology, 72, 592-603.

Emmons, R. A. (1991). Personal strivings, daily life events, and psychological and physical well-being. Journal of Personality, 59, 453-472.

Festinger, L. (1954). A theory of social comparison processes. Human Relations, 7, 117-140.

Foa, U. G. (1961). Convergences in the analysis of the structure of interpersonal behavior. Psychological Review, 68, 341-355.

Foa, U., \& Foa, E. (1974). Societal structures of the mind. Springfield, IL: Charles C Thomas.

Gifford, R. (1991). Mapping nonverbal behavior on the interpersonal circle. Journal of Personality and Social Psychology, 61, 279-288.

Giordano, C., Wood, J. V., \& Michela, J. L. (2000). Depressive personality styles, dysphoria, and social comparisons. Journal of Personality and Social Psychology, 79, 438-451.

Goethals, G. R., \& Darley, J. M. (1977). Social comparison theory: An attributional approach. In J. M. Suls \& R. L. Miller (Eds.), Social comparison processes: Theoretical and empirical perspectives (pp. 259-278). Washington, DC: Hemisphere Publication Services.

Gurtman, M. B (1999). Social competence: An interpersonal analysis and reformulation. European Journal of Psychological Assessment, 15, 233 245

Heck, S. A., \& Pincus, A. L. (2001). Agency and communion in the structure of parental representations. Journal of Personality Assessment, $76,180-184$

Hegelson, V. S., \& Taylor, S. E. (1993). Social comparisons and adjust- ment among cardiac patients. Journal of Applied Social Psychology, 23, $1171-1195$

Hill, R. W., Zrull, M. C., \& Turlington, S. (1997). Perfectionism and interpersonal problems. Journal of Personality Assessment, 69, 81-103.

Horowitz, L. M., Alden, L. E., Wiggins, J. S., \& Pincus, A. L. (2000). Inventory of interpersonal problems manual. San Antonio, TX: Psychological Corporation.

Horowitz, L. M., Krasnoperova, E. N., Tatar, D. G., Hansen, M. B., Person, E. A., Galvin, K. L., \& Nelson, K. L. (2001). The way to console may depend on the goal: Experimental studies of social support. Journal of Experimental Social Psychology, 37, 49-61.

Horowitz, L. M., Locke, K. D., Morse, M. B., Waikar, S. V., Dryer, D. C., Tarnow, E., \& Ghannam, J. (1991). Self-derogations and interpersonal theory. Journal of Personality and Social Psychology, 61, 68-79

Kenny, D. A., Kashy, D. A., \& Bolger, N. (1998). Data analysis in social psychology. In D. T. Gilbert, S. T. Fiske, \& G. Lindzey (Eds.), The handbook of social psychology (4th ed., pp. 233-265). New York: McGraw-Hill.

Kiesler, D. J. (1996). Contemporary interpersonal theory and research: Personality, psychopathology, and psychotherapy. New York: Wiley.

Locke, K. D. (2000). Circumplex scales of interpersonal values: Reliability, validity, and applicability to interpersonal problems and personality disorders. Journal of Personality Assessment, 75, 249-267.

Locke, K. D., \& Horowitz, L. M. (1990). Satisfaction in interpersonal interactions as a function of similarity in level of dysphoria. Journal of Personality and Social Psychology, 58, 823-831.

Locke, K. D., \& Nekich, J. (2000). Agency and communion in naturalistic social comparison. Personality and Social Psychology Bulletin, 26, $864-874$

Lockwood, P. (2002). Could it happen to you? Predicting the impact of downward comparisons on the self. Journal of Personality and Social Psychology, 82, 343-358.

Lockwood, P., \& Kunda, Z. (1997). Superstars and me: Predicting the impact of role models on the self. Journal of Personality and Social Psychology, 73, 91-103.

Matano, R., \& Locke, K. D. (1995). Personality disorder scales as predictors of interpersonal problems of alcoholics. Journal of Personality Disorders, 9, 62-67.

McAdams, D. P. (1982). Experiences of intimacy and power: Relationships between social motives and autobiographical memory. Journal of Personality and Social Psychology, 42, 292-302.

McAdams, D. P. (1992). The intimacy motive scoring system. In C. P. Smith (Ed.), Handbook of thematic content analysis (pp. 229-253). New York: Cambridge University Press.

Miller, D. T., Turnbull, W., \& McFarland, C. (1988). Particularistic and universalistic evaluation in the social comparison process. Journal of Personality and Social Psychology, 55, 908-917.

Millon, T. (1994). Manual for the Millon Clinical Multiaxial Inventory-III. Minneapolis, MN: National Computer Systems.

Mussweiler, T., \& Bodenhausen, G. (2002). I know you are, but what am I? Self-evaluative consequences of judging in-group and out-group members. Journal of Personality and Social Psychology, 82, 19-32.

Newcomb, T. M. (1961). The acquaintance process. New York: Holt, Rinehart \& Winston.

Nezlek, J. B. (2001). Multilevel random coefficient analyses of event- and interval-contingent data in social and personality psychology research. Personality and Social Psychology Bulletin, 27, 771-785.

Oishi, S., Diener, E., Suh, E., \& Lucas, R. E. (1999). Value as a moderator in subjective well-being. Journal of Personality, 67, 157-184.

Olson, B., \& Evans, D. L. (1999). The role of the Big Five personality dimensions in the direction and affective consequences of everyday social comparisons. Personality and Social Psychology Bulletin, 25, $1498-1508$

Pelham, B. W., \& Wachsmuth, J. O. (1995). The waxing and waning of the 
social self: Assimilation and contrast in social comparison. Journal of Personality and Social Psychology, 69, 825-838.

Pincus, A. L., \& Wilson, K. R. (2001). Interpersonal variability in dependent personality. Journal of Personality, 69, 223-251.

Ruiz, J. M., Smith, T. W., \& Rhodewalt, F. (2001). Distinguishing narcissism and hostility: Similarities and differences in interpersonal circumplex and five-factor correlates. Journal of Personality Assessment, 76, 537-555.

Salekin, R. T., Trobst, K. K., \& Krioukova, M. (2001). Construct validity of psychopathy in a community sample: A nomological net approach. Journal of Personality Disorders, 15, 425-441.

Schachter, S. (1959). The psychology of affiliation. Stanford, CA: Stanford University Press.

Stapel, D. A., \& Koomen, W. (2000). Distinctiveness of others, mutability of selves: Their impact on self-evaluations. Journal of Personality and Social Psychology, 79, 1068-1087.

Stapel, D. A., \& Koomen, W. (2001). I, we, and the effects of others on me: How self-construal level moderates social comparison effects. Journal of Personality and Social Psychology, 80, 766-781.

Taylor, S. E., \& Lobel, M. (1989). Social comparison activity under threat: downward evaluation and upward contacts. Psychological Review, 96, 569-575.

Tesser, A. (1988). Toward a self-evaluation maintenance model of social behavior. In L. Berkowitz (Ed.), Advances in experimental social psychology: Vol. 21 (pp. 181-227). San Diego, CA: Academic Press.

Tesser, A. (1991). Emotion in social comparison and reflection processes. In J. Suls \& T. Wills (Eds.), Social comparison processes: Contemporary theory and research (pp. 115-145). Hillsdale, NJ: Erlbaum.

Tesser, A. (2000). On the confluence of self-esteem maintenance mechanisms. Personality and Social Psychology Review, 4, 290-299.

Testa, M., \& Major, B. (1990). The impact of social comparisons after failure: The moderating effects of perceived control. Basic \& Applied Social Psychology, 11, 205-218.

Trobst, K. K. (2000). An interpersonal conceptualization and quantification of social support transactions. Personality and Social Psychology Bulletin, 26, 971-986.

Van der Zee, K. I., Buunk, B. P., DeRuiter, J. H., Tempelaar, R., VanSonderen, E., \& Sanderman, R. (1996). Social comparison and the subjective well-being of cancer patients. Basic \& Applied Social Psychology, $18,453-468$

Wheeler, L. (2000). Individual differences in social comparison. In J. Suls $\&$ L. Wheeler (Eds.), Handbook of social comparison: Theory and research (pp. 141-158). New York: Plenum Press.

Wheeler, L., Martin, R., \& Suls, J. (1997). The proxy model of social comparison for self-assessment of ability. Personality \& Social Psychology Review, 1, 54-61.
Wheeler, L., \& Miyake, K. (1992). Social comparison in everyday life Journal of Personality and Social Psychology, 62, 760-773.

Wheeler, L., Shaver, K., Jones, R., Goethals, G., Cooper, J., Robinson, J., Gruder, C., \& Butzine, K. (1969). Factors determining choice of a comparison other. Journal of Experimental Social Psychology, 5, 219 232 .

Widiger, T. A., \& Hagemoser, S. (1997). Personality disorders and the interpersonal circumplex. In R. Plutchik \& H. R. Conte (Eds.), Circumplex models of personality and emotions (pp. 299-325). Washington, DC: American Psychological Association.

Wiggins, J. S. (1979). A psychological taxonomy of trait-descriptive terms: The interpersonal domain. Journal of Personality and Social Psychology, 33, 409-420.

Wiggins, J. S., Phillips, N., \& Trapnell, P. (1989). Circular reasoning about interpersonal behavior: Evidence concerning some untested assumptions underlying diagnostic classification. Journal of Personality and Social Psychology, 56, 296-305.

Wiggins, J. S., \& Trobst, K. (1999). The fields of interpersonal behavior. In L. Pervin \& O. John (Eds.), Handbook of personality: Theory and research (2nd ed., pp. 653-670). New York: Guilford Press.

Wills, T. A. (1991). Similarity and self-esteem in downward comparison. In J. Suls \& T. Wills (Eds.), Social comparison processes: Contemporary theory and research (pp. 51-78). Hillsdale, NJ: Erlbaum.

Winter, D. G. (1992). A revised scoring system for the power motive. In C. P. Smith (Ed.), Handbook of thematic content analysis (pp. 311-324). New York: Cambridge University Press.

Woike, B., Gershkovich, I., Piorkowski, R., \& Polo, M. (1999). The role of motives in the content and structure of autobiographical memory. Journal of Personality and Social Psychology, 76, 600-612.

Wood, J. V. (1996). What is social comparison and how should we study it? Personality and Social Psychology Bulletin, 22, 520-537.

Wood, J. V., \& Lockwood, P. (1999). Social comparisons in dysphoric and low self-esteem people. In R. Kowalski \& M. Leary (Eds.), The social psychology of emotional and behavioral problems: Interfaces of social and clinical psychology (pp. 97-135). Washington, DC: American Psychological Association.

Wood, J. V., Michela, J. L., \& Giordano, C. (2000). Downward comparison in everyday life: Reconciling self-enhancement models with the moodcognition priming model. Journal of Personality and Social Psychology, $79,563-579$.

Zuroff, D. C., Moskowitz, D. S., \& Cote, S. (1999). Dependency, selfcriticism, interpersonal behaviour and affect: Evolutionary perspectives. British Journal of Clinical Psychology, 38, 231-250.

Received October 2, 2001

Revision received August 26, 2002

Accepted September 5, 2002 